\title{
Longitudinal Study of Lung Function, Exhaled Nitric Oxide and Level of Asthma Control in Children and Adolescents
}

\author{
Uarlhinson Oliveira Andrade ${ }^{1}$, Giselle Santos Magalhães ${ }^{2}$, Nulma Souto Jentzsch ${ }^{3,4}$ \\ and Maria Glória Rodrigues-Machado ${ }^{1^{*}}$
}

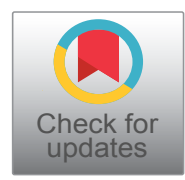

${ }^{1}$ Pós-Graduação em Ciências da Saúde, Faculdade Ciências Médicas-Minas Gerais, Belo Horizonte, MG, Brazil

${ }^{2}$ Departamento de Fisiologia e Biofísica, Universidade Federal de Minas Gerais, Belo Horizonte, MG, Brazil

${ }^{3}$ Departamento de Medicina, Faculdade Ciências Médicas-Minas Gerais, Belo Horizonte, MG, Brazil

${ }^{4}$ Unidade de Referência de Saúde Campos Sales, da Prefeitura de Belo Horizonte (URS Campos Sales-SUS BH), Belo Horizonte, MG, Brazil

*Corresponding author: Maria Glória Rodrigues-Machado, PhD, Pós-Graduação Ciências Médicas, Faculdade Ciências Médicas-Minas Gerais, 30130-110 Alameda Ezequiel Dias 275-Centro, Belo Horizonte, Minas Gerais, Brazil, Tel: 55-313248-7130, Fax: 55-31-3248-7132

\begin{abstract}
Introduction: Although recent guidelines focus on asthma control, a significant number of patients remains poorly controlled.

Objective: To evaluate the longitudinal effects of corticosteroids on lung function, inflammation and asthma control.

Methods: 22 asthmatic children and adolescents (10.5 \pm 2.55 years) participated of three visits (2 months a part). On each visit spirometry, fractional exhaled nitric oxide (FeNO), level of asthma control (Asthma control test-ACT), and asthma severity were assessed. The beclomethasone (Clenil $\left.{ }^{\circledR} 250 \mu \mathrm{g} / \mathrm{jato}-L a b o r a t o r y ~ C h i e s i-B r a z i l\right)$, at a dose of 1 jet $12 / 12 \mathrm{~h}$, started on the first visit.

Results: One patient was classified as having controlled asthma, 10 partially controlled asthma (PCA), and 11 uncontrolled asthma (UC). On the third visit, 14 patients were classified as PCA and 7 UC. The FEV $/$ /FVC (\%) significantly increased from baseline to the third visit $(p=$ 0.0098 ). The number of asthma patients with low levels of FeNO increased from 9 to 16 patients and the number of asthma patients with intermediate levels of FeNO reduced from 7 to 2 patients, considering the first and third visits. Dispersion of FeNO levels were widely in the study sample. As expected, the FeNO correlated inversely with $\mathrm{FEV}_{1} / \mathrm{FVC}(\%)$ in all evaluations. The baseline ACT score was positively correlated with baseline $\mathrm{FEV}_{1} \%(r=0.4480$, $\mathrm{p}=0.0417)$. FeNO levels, $\mathrm{FEV}_{1}(\%), \mathrm{FEV}_{1} / \mathrm{CVF}(\%)$, and ACT scores did not differ between atopic and non-atopic subgroups in 3 time points.
\end{abstract}

Conclusion: Treatment with corticosteroids improved the classification of the asthma control level. Despite the great dispersion of the FeNO levels, this biomarker correlated inversely with Tiffeneau index in the three evaluations.

\section{Keywords}

Asthma control test, Atopy, Inflammation, Nitric oxide, IgE sensitization

\section{Introduction}

Asthma is a heterogeneous disease characterized by chronic inflammation of the airways, defined by history of respiratory symptoms of wheezing, breathlessness, chest tightness and coughing, along with chronic airflow limitation [1]. This disease presents different phenotypes [2] which may be related to the natural history of the disease, with immune, inflammatory and structural characteristics of the airways and clinical control. The inflammation, structural changes caused by the maintenance of the inflammatory process and the imbalance between extracellular matrix synthesis and degradation lead to reduction in airway caliber and bronchial hyperresponsiveness [1]. Epidemiological studies have shown that asthma is now the most common chronic disease among children and is a major cause of absenteeism from school and adults at work.

Citation: Andrade UO, Magalhães GS, Jentzsch NS, Rodrigues-Machado MG (2019) Longitudinal Study of Lung Function, Exhaled Nitric Oxide and Level of Asthma Control in Children and Adolescents. Int Arch Nurs Health Care 5:117. doi.org/10.23937/2469-5823/1510117

Accepted: January 28, 2019: Published: January 30, 2019

Copyright: (c) 2019 Andrade UO, et al. This is an open-access article distributed under the terms of the Creative Commons Attribution License, which permits unrestricted use, distribution, and reproduction in any medium, provided the original author and source are credited. 
Furthermore, asthma is associated with a significant mortality rate $[3,4]$.

Pulmonary function test is useful for evaluating airflow obstruction, reversibility of airway obstruction by bronchodilator test and excessive variation in lung function during the visits. Forced expiratory volume in the first second of forced vital capacity $\left(\mathrm{FEV}_{1}\right)$ down is a strong independent predictor of future risk of exacerbations and is a risk factor for the decline in lung function [1].

The role of nitric oxide exhaled fraction (FeNO) in the management of asthma is not well established. The exhaled nitric oxide is considered a marker of airway inflammation and is closely associated with bronchial eosinophilia [5]. According to some authors, this biomarker of airway can be used to define the phenotype of asthma, predict the development and exacerbation of the disease, predict responsiveness to corticosteroids and assess the level of asthma control $[6,7]$. Furthermore, it was demonstrated that patients with higher levels of exhaled nitric oxide have higher rates of decline in FEV [8]. However, none of the studies conducted so far has shown that the use of FeNO was better than current asthma guidelines to control asthma exacerbations. Furthermore, there is a wide variation in exhaled nitric oxide levels between individuals, which may reflect the heterogeneity of the activity of nitric oxide synthase (NOS) in the epithelium and/or the contribution of other non-eosinophilic epithelial NOS activity [9].

The goal of asthma management is to control the disease, which refers to the extent to which the manifestations of asthma are reduced or resolved by the treatment, and comprises two distinct domains: symptom control and reducing future risk events adverse [1]. Several instruments have been used to assess asthma control. The asthma control test (ACT), one of the tools most commonly used in clinical practice, consists of five questions that assess signs and symptoms and rescue medication use ( $\beta 2$ agonist short duration) in the last four weeks [10]. The validity and responsiveness of the TCA to changes in asthma control have been documented in several studies [11-14].

Drug treatment is based on the reduction of the inflammatory process, with the inhaled corticosteroid election therapy in asthma. Inhaled corticosteroids reduce the frequency and severity of exacerbations, the number of hospitalizations and visits to emergency services, as well as improved the quality of life, lung function and hyperactivity bronchial as well, decreases exercise-induced bronchoconstriction [15]. Recent study Marchioro, et al., it showed that the vast majority of patients with asthma in Brazil does not have their disease under control, according to international criteria. According to these authors, the maintenance medications of asthma control are still underused in Brazil, and the use of relief medications and oral corticosteroids are more frequent in patients with partially controlled or uncontrolled asthma.

Asthma is typically recognized by an eosinophilic inflammatory airway disease. However, the association between inflammation and clinical control of asthma is not well established. Studies have shown that the reduction of corticosteroids is associated with loss of clinical control and increased eosinophils in sputum. Due to inadequate control of asthma, this study evaluated the effect of corticosteroid on the association between lung function (used for diagnosis and classification of asthma), FeNO (an eosinophilic inflammation marker of the airways) and asthma control (control test asthma) in children and adolescents without prior use of inhaled corticosteroids.

\section{Methods}

\section{Sample calculation}

The sample size was obtained to detect a difference of $3 / 5$ of the standard deviation of the difference between two measurements of the same individual, lengthwise. The $5 \%$ level of significance and power of $80 \%$ was obtained $n=22$. The formula [16] was used:

$$
\mathrm{n}=\left[\frac{\left(\mathrm{Z}_{1-\alpha / 2}+\mathrm{Z}_{1-\beta}\right) \mathrm{Sd}}{\overline{\mathrm{d}}}\right]^{2}
$$

Where $\overline{\mathrm{d}}$ and Sd denote the mean and standard deviation of the differences between the two measures (lengthwise) and $Z_{(1-\alpha / 2)}$ and $Z_{(1-\beta)}$ are quantiles of the normal distribution related to the level of significance and power, respectively. The sample size was 22 obtained.

\section{Type, location and period of the study}

This is a prospective, longitudinal study involving 22 children and adolescents with asthma, classified with persistent asthma and moderate to severe persistent asthma. The study was conducted at the Secondary Reference Unit Campos Sales in Belo Horizonte, Minas Gerais, in the period from February to December 2015. During this period there were three clinical evaluations, with an average interval of two months each. The participants were referred by general practitioners and pediatricians in primary care settings.

\section{Experimental protocol}

After the rest period and fasting for at least 1 hour, were carried out of nitric oxide exhaled and anthropometric measurements. After the clinical examination were performed spirometry and bronchodilator test. It was later performed allergy tests and reading after 15 minutes. Finally, we applied the asthma control test. 


\section{Allergic cutaneous test}

The patients underwent skin test Immunotech ${ }^{\circledR}$ (Rio de Janeiro, Rio de Janeiro, Brazil) whose panel contained in the kit 11 kinds of reagents with 02 controls, $02 \mathrm{ml}$ positive one (Test EP histamine $10 \mathrm{mg} /$ $\mathrm{ml}$ ) and another negative (Test EP saline) to $03 \mathrm{ml}$ and the other nine types Dermatophagoides pteronyssinus $20 \%$, Dermatophagoides farinae $20 \%$ Blomia tropicalis $5 \%$, Alternaria alternata 5\%, Aspergillus fumigatus 5\%, Cockroach 5\%, Mosquito 5\%, Dog epithelium 5\%, Cat epithelium $5 \%$, each bottle with $3 \mathrm{ml}$. The kit was kept as standard, from 2 to $8{ }^{\circ} \mathrm{C}$, and its validity was until 01.31.2016.

For the test the pre-cleaning of the skin was performed in the ventral face average (volar) forearms, with running water and soap degermante commonly used in healthcare facilities. ID $(13 \times 3.8)$, single use, later discarded in an appropriate place an intradermal sterile needle was used. After holding the first pick in the skin with the needle was marked the limit of at least $3 \mathrm{~cm}$ between the locations of the other picks. The needle was inserted perpendicular to the skin at a small pressure. Subsequently, a drop of controls for comparison with other reagents was placed. After each pick, respecting the space defined earlier, the above antigens were put through a dropper forbade each vial individually, with no contamination by other reagents. It determined also the distance of at least $1 \mathrm{~cm}$ for the application, with no contamination of the dropper by the skin. 15 minutes after application of the last reagent, the reading of the papules formed was carried out which should be at least $3 \mathrm{~mm}$ in diameter to be confirmed as a positive reaction to the reagent, and recorded in a proper form. At the end of the readings was asked participants to wash the place with water and dried up with paper towels. Patients were alerted to the persistence of itching, swelling and redness at the pick of the place, being discouraged from using any kind of ointment, cream, lotion or product that is not prescribed by the doctor as well as to avoid scratching or rubbing [17-20].

Children and adolescents using systemic allergy Topics presence of lesions and dermatitis at the site of the test; anaphylaxis history; crisis of asthma and rhinitis in before the test day or 5 days and the presence of fever were free of tests.

\section{Exhaled fraction evaluation nitric oxide}

For the test FeNO was used $\mathrm{NIOX} \mathrm{MINO}^{\circledR}$ (Aerocrine AB, Solna, Sweden) as recommended by the ATS [21] and by the manufacturer. The exhalation flow rate was $50 \mathrm{ml} / \mathrm{s}$, after expiry of the test time until the reading from 5 to 30 seconds reading time of about $34 \mathrm{~s}$ [22]. 3 measurements on each participant, with 10-minute interval between them were conducted. In the final analysis, it was considered the average of
Table 1: Hay reference values according to age.

\begin{tabular}{|l|l|l|l|}
\hline & Low & Intermediate & High \\
\hline $\begin{array}{l}\text { Values of FeNO }(\mathrm{ppb}), \text { patients } \\
\geq 12 \text { years of age }\end{array}$ & $<25$ & $25-50$ & $>50$ \\
\hline $\begin{array}{l}\text { Values of FeNO }(\mathrm{ppb}), \text { patients } \\
<12 \text { years of age }\end{array}$ & $<20$ & $20-35$ & $>35$ \\
\hline
\end{tabular}

Source: Dweik RA, et al. [21].

the measurements. In interpreting the values was performed using the parameters of Table 1 as indicated by ATS [21] and the manufacturer [23]. The patients rest 15 minutes before the test. In previous contact patients were instructed to make them fast for a minimum of one hour. The tests were performed in a standing position.

\section{Asthma control test}

The asthma control test (ACT) was applied to all queries, always by the same interviewer. The ACT has five items that relate to the symptoms, rescue medication use and effect of asthma on daily activities without the need to function measurements pulmonar. Each question has an answer scale whose score ranges from 1 to 5 , resulting in a total score test between 5 and 25 points. The score of 25 refers to total control. The score between 20 and 24 points indicates partially controlled asthma, and a score below 20 means uncontrolled asthma, below 20 means uncontrolled asthma [24-26].

\section{Spirometry}

For spirometry was used machine (VM1 ATS, Clement Clarke, CE0120, Made in the U.K.), with disposable polypropylene nozzle in the standing position and always by the same observer. The technical procedures, the criteria for acceptability and reproducibility followed the standards of the ATS/ERS. The parameters analyzed were forced vital capacity (FVC), forced expiratory volume in one second FVC $\left(F_{1} V_{1}\right)$ and Tiffeneau in$\operatorname{dex}\left(F_{1} V_{1} / F V C\right)$. Children and adolescents were instructed to perform a maximal inspiration and then exhale all the air volume with maximum effort with his mouth properly attached to the mouth, avoiding air leakage. For proof bronchodilator salbutamol have been used four jets (Aerolim ${ }^{\circledR}$ - $100 \mathrm{~g} / \mathrm{jet}$ ), with a minimum interval of one minute between them. After 15 minutes the test was repeated and the bronchodilator response was considered positive for values over $12 \%$ in $\mathrm{FEV}_{1}$ (\% predicted) [1]. For the predicted values were used the equations of Polgar and Promadhat [27].

\section{Inclusion and exclusion criteria}

The study included patients of both genders, with persistent asthma or persistent moderate and severe, classified according to the criteria of the GINA (2015), with no history of treatment with inhaled corticosteroids 30 days before the first visit (baseline), at the age of 7-15 years old, and able to perform spirometry and measurement of FeNO. Exclusion 
Table 2: Sample characterization.

\begin{tabular}{|c|c|}
\hline Sample (F/M) & $11 / 11$ \\
\hline \multicolumn{2}{|l|}{ Race } \\
\hline White & 8 \\
\hline Brown & 12 \\
\hline Black & 2 \\
\hline Age (years) & $10.5 \pm 2.55$ \\
\hline Weight (Kg) & $39.5 \pm 9.69$ \\
\hline Stature $(\mathrm{cm})$ & $141.6 \pm 13.60$ \\
\hline BMI $\left(\mathrm{Kg} / \mathrm{m}^{2}\right)$ & $19.6 \pm 3.03$ \\
\hline Eutrophic & $18.6 \pm 3.67$ \\
\hline Overweight & $19.1 \pm 0.93$ \\
\hline Obesity & $22.8 \pm 2.03$ \\
\hline
\end{tabular}

\begin{tabular}{|c|c|}
\hline \multicolumn{2}{|l|}{ Allergy skin tests } \\
\hline Atopic & 16 \\
\hline Non-atopic & 6 \\
\hline \multicolumn{2}{|c|}{ Classification of asthma severity } \\
\hline Persistent & 8 \\
\hline Moderate persistent & 8 \\
\hline Severe persistent & 6 \\
\hline
\end{tabular}

\begin{tabular}{|l|l|}
\hline \begin{tabular}{l} 
Spirometric data \\
\hline FVC $(\mathrm{ml})$
\end{tabular} & $1.82 \pm 0.75(0.66-4.00)$ \\
\hline FVC $(\%)$ & $79.0 \pm 17.48(32-120.5)$ \\
\hline FEV $_{1}(\mathrm{ml})$ & $1.64 \pm 0.69(0.66-3.97)$ \\
\hline $\mathrm{FEV}_{1}(\%)$ & $78.8 \pm 15.08(34.90-104.50)$ \\
\hline FEV $_{1} / \mathrm{FVC}(\%)$ & $93.7 \pm 11.10(52.50-102.10)$ \\
\hline
\end{tabular}

\begin{tabular}{|c|l|}
\hline Bronchodilator test & \\
\hline Positive & 5 \\
\hline Negative & 17 \\
\hline
\end{tabular}

Data are expressed as mean \pm SD. F: Female; M: Male; BMI: Body mass index; FVC: Forced vital capacity; FEV: Forced expiratory volume in one second FVC. Fractional of exhaled nitric oxide. Figures in brackets represent the minimum and maximum values of the measurements.

criteria were chronic diseases besides asthma, recent airway infections, presence or history of fever in the last 30 days, exacerbation of asthma, smoking and inability to perform the proposed procedures.

\section{Ethical aspects}

All procedures were conducted in accordance with the Declaration of Helsinki and with the approval of the Institutional Ethics Committee (0004.0.418.000-11).

\section{Statistical analysis}

Variables were described as measures of central tendency (mean) and variability (standard deviation). To normalize the data, we used the KolmogorovSmirnov normality test. Comparisons of the variables of pulmonary function testing, pre- and postbronchodilator, were performed using the paired $\mathrm{t}$ test. For longitudinal comparisons of variables was used One Way ANOVA or Kruskal-Wallis when indicated. To analyze the associations between different variables and between the same variable, according to the visits, we used the Pearson or Spearman test when indicated. The FeNO was categorized and analyzed by age group and their comparison between visits were not normally distributed and the Kruskal Wallis test and Mann Whitney tests were used. Data analysis was performed with the Graphpad Prism software version 6.0.0 level of significance was considered at $p<0.05$.

\section{Results}

Thirty-seven children and adolescents eligible for the study, between January and November 2015, 22 participated in three visits and completed the proposed procedures. Fourteen of them appeared in only one query and/or failed to perform the proposed tests (FeNO and spirometry). A child dropped from the study.

Table 2 show the characteristics of the 22 patients in the study. There was no difference in the number of participants divided by gender. In regard to race it has been observed that most participants consisted of brown (54.5\%), white (36.4\%) and black (9.1\%). In allergy testing was predominantly atopic asthma $(72.7 \%)$. In the classification of asthma severity was observed that $72.7 \%$ of participants had persistent and moderate asthma, and only $27.3 \%$ severe. The bronchodilator test was negative in $77.3 \%$ of patients with asthma.

Data from the longitudinal evaluation of spirometry, FeNO, the control tests of asthma and the symptoms are shown in Table 3. For the presentation of FeNO results, patients were divided into subgroups for those aged < 12 years and $\geq 12$ years and later into low, intermediate and high values of this variable as the standardization of the manufacturer. The mean score of the ACT was $19: 36 \pm 3.27$ at baseline, $20.0 \pm 4: 49$ and $20.77 \pm 4.02$ in the second and third visits, respectively. However, the increase was significant only between the second and third visit $(p=0.0309)$. The TCA correlated moderately and positively with $\mathrm{FEV}_{1} \%$ at baseline $(r=0.4480, p=$ 0.0417). In relation to data in lung function, $\mathrm{FEV}_{1}(\%)$ did not vary significantly between visits. Otherwise, the $\mathrm{FEV}_{1} / \mathrm{FVC}$ ratio (\%) significantly increased basal query to the third visit $(p=0.0098)$. Levels of FeNO, FEV $(\%)$, the FVC, FEV $_{1} /$ FVC ratio (\%), and ACT scores did not differ between atopic and non-atopic subgroups in 3 time points.

\section{Symptoms reported during the visits}

Reported symptoms shown in Table 4 indicate a predominance of cough complaint, both daytime as night with little variation between appointments, but with a slight decrease compared with the baseline visit $3(10 / 13$ to $8 / 8)$. Chest pain was unreported in both the basal (04 participants) as the third visit (03 participants). Table 4 show the mean \pm SD of the absolute values according to the age and levels of severity of FeNO.

The FeNO correlated significantly between the banal and the second visit, as well as the second and third 
Table 3: Longitudinal evaluation data of the fraction of exhaled nitric oxide of the control tests of asthma and lung function and symptoms reported in the consultations.

\begin{tabular}{|c|c|c|c|}
\hline & Basal & 2 Visit & 3 Visit \\
\hline \multicolumn{4}{|l|}{ FeNO (n) } \\
\hline $\begin{array}{l}\text { Low } \\
<12 \text { years }(<20 \mathrm{ppb}) \\
\geq 12 \text { years }(<25 \mathrm{ppb})\end{array}$ & 9 & 12 & 16 \\
\hline $\begin{array}{l}\text { Intermediate } \\
<12 \text { years }(20-35 \mathrm{ppb}) \\
\geq 12 \text { years }(25-50 \mathrm{ppb})\end{array}$ & 7 & 6 & 2 \\
\hline $\begin{array}{l}\text { High } \\
<12 \text { years }(>35 \mathrm{ppb}) \\
\geq 12 \text { years }(>50 \mathrm{ppb})\end{array}$ & 6 & 4 & 4 \\
\hline \multicolumn{4}{|l|}{ TCA (n) } \\
\hline Uncontrolled & 11 & 5 & 7 \\
\hline Poorly controlled & 10 & 17 & 14 \\
\hline Controlled & 1 & 0 & 1 \\
\hline $\mathrm{FEV}_{1} \%$ & $\begin{array}{l}76.41 \pm 15.15 \\
(38.1-97.2)\end{array}$ & $\begin{array}{l}76.49 \pm 16.68 \\
(34.9-104.5)\end{array}$ & $\begin{array}{l}79.95 \pm 13.60 \\
(50.5-102.6)\end{array}$ \\
\hline $\mathrm{FEV}_{1} / \mathrm{FVC} \%$ & $\begin{array}{l}84.96 \pm 13.61 \\
(52.5-100.0)\end{array}$ & $\begin{array}{l}92.42 \pm 10.50 \\
(70.2-102.1)\end{array}$ & $\begin{array}{l}93.55 \pm 6.47 \\
(77.2-100.0)\end{array}$ \\
\hline \multicolumn{4}{|l|}{ Symptoms (n) } \\
\hline Cough day night & $10 / 13$ & $10 / 10$ & $8 / 8$ \\
\hline Wheezing & 7 & 6 & 4 \\
\hline Tiredness & 7 & 5 & 5 \\
\hline Chest pain & 4 & 1 & 3 \\
\hline
\end{tabular}

FeNO: Fractional of exhaled nitric oxide; ACT: Asthma control test; FEV $\%$ : Forced expiratory volume in 1 second of the forced vital capacity $(F V C)$ and $F E V_{1} / F V C$. Data are expressed as mean $\pm S D$ (minimum and maximum) for $F E V_{1}$ and $F E V_{1} / F V C$.

Table 4: FeNO levels according to age and their respective benchmarks.

\begin{tabular}{|l|l|l|l|}
\hline FeNO & Basal & 2 Visit & 3 Visit \\
\hline & & $<12$ years & \\
\hline Low & $12.43 \pm 4.65$ & $10.29 \pm 3.35$ & $12.09 \pm 4.57$ \\
\hline Intermediate & $23.00 \pm 3.94$ & $25.60 \pm 3.78$ & $21.00 \pm 0.0$ \\
\hline High & $58.00 \pm 2.83$ & $64.00 \pm 14.14$ & $54.00 \pm 11.31$ \\
\hline & & $\geq 12$ years & \\
\hline Low & $13.50 \pm 6.36$ & $17.60 \pm 7.64$ & $19.40 \pm 4.16$ \\
\hline Intermediate & $30.33 \pm 8.51$ & $31.00 \pm 12.73$ & $32.00 \pm 0.0$ \\
\hline High & $80.67 \pm 2.52$ & $84.00 \pm 0.0$ & $57.00 \pm 1.41$ \\
\hline
\end{tabular}

Show the mean \pm SD of the absolute values according to the age and levels of severity of FeNO.

visits (Figure 1). As expected FeNO correlated inversely with Tiffeneau index assessed at baseline as well in the second and third visits (Figure 2).

The ACT score of Baseline was positively correlated with $\mathrm{FEV}_{1} \%$ predicted from the baseline visit $(r=0.4480$, $p=0.0417$ ) in Figure 3.

\section{Discussion}

Drug therapy of asthma is the cornerstone of treatment and the optimal use of medicines can, in most cases, help patients control the symptoms and reduce the risk of future morbidity. Therefore, the evaluation and monitoring should be performed regularly to reassess and adjust the treatment [1]. Due to the heterogeneity of asthma, multiple biomarkers are required for the diagnosis and management [9].
This study evaluated the effects of beclomethasone on lung function, airway inflammation and asthma control in children and adolescents in three consecutive visits with an interval of two months between them. Lung function, as measured by the ratio $\mathrm{FEV}_{1} / \mathrm{FVC}(\%)$ increased significantly from the first to the third visit. Furthermore, it was observed that the level of exhaled inversely correlated with the increase in the ratio $\mathrm{FEV}_{1} /$ FVC (\%) evaluated in three visits. The level of asthma control, as assessed by ACT, positively correlated with $\mathrm{FEV}_{1} \%$, only on the first visit. The FeNO levels, $\mathrm{FEV}_{1}(\%)$, $\mathrm{FEV}_{1} / \mathrm{FVC}(\%)$ and the ACT score did not differ between participants with atopic asthma, non-atopic, defined by a positive skin test for all three times.

In the classification of asthma severity was observed that $72.7 \%$ of participants had mild persistent and persistent asthma, and only $27.3 \%$ severe persistent. The level of asthma control participants consisted primarily of partly controlled asthma (45.5\%) and non-controlled (50\%). In the third visit, the proportion of participants with partially controlled asthma increased to $63.63 \%$ and uncontrolled decreased to $31.31 \%$, suggesting an increase in asthma control from the beginning of the introduction of corticosteroids for asthma control. The predominant symptom in this sample was coughing complaint, both daytime as night with little variation between appointments, but with a slight decrease comparing the first and third visit. Chest pain was rarely reported during treatment. 

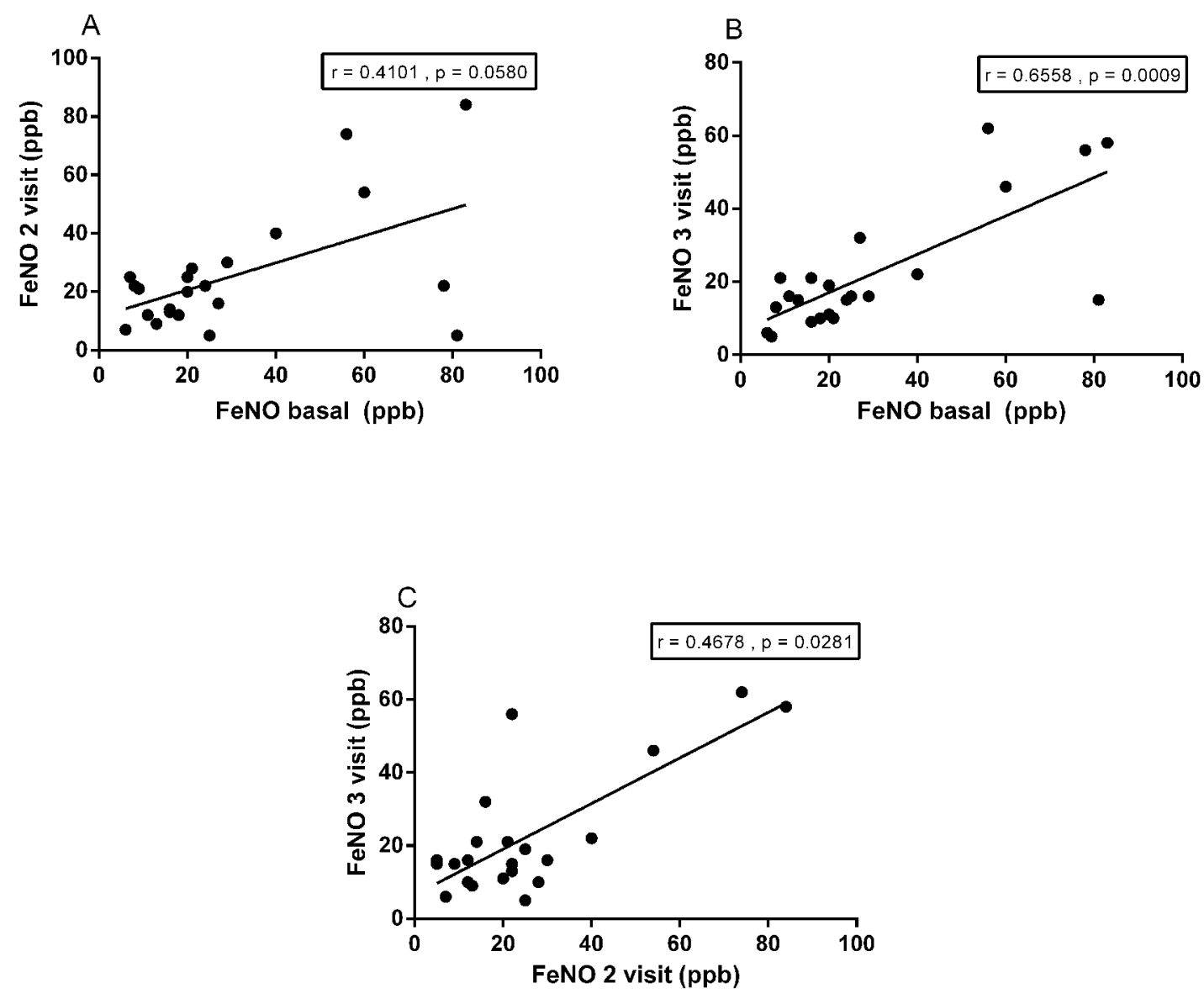

Figure 1: Relationship of fraction of exhaled nitric oxide (FeNO) in basal visits, $2^{\text {nd }}$ and $3^{\text {rd }}$ visits.
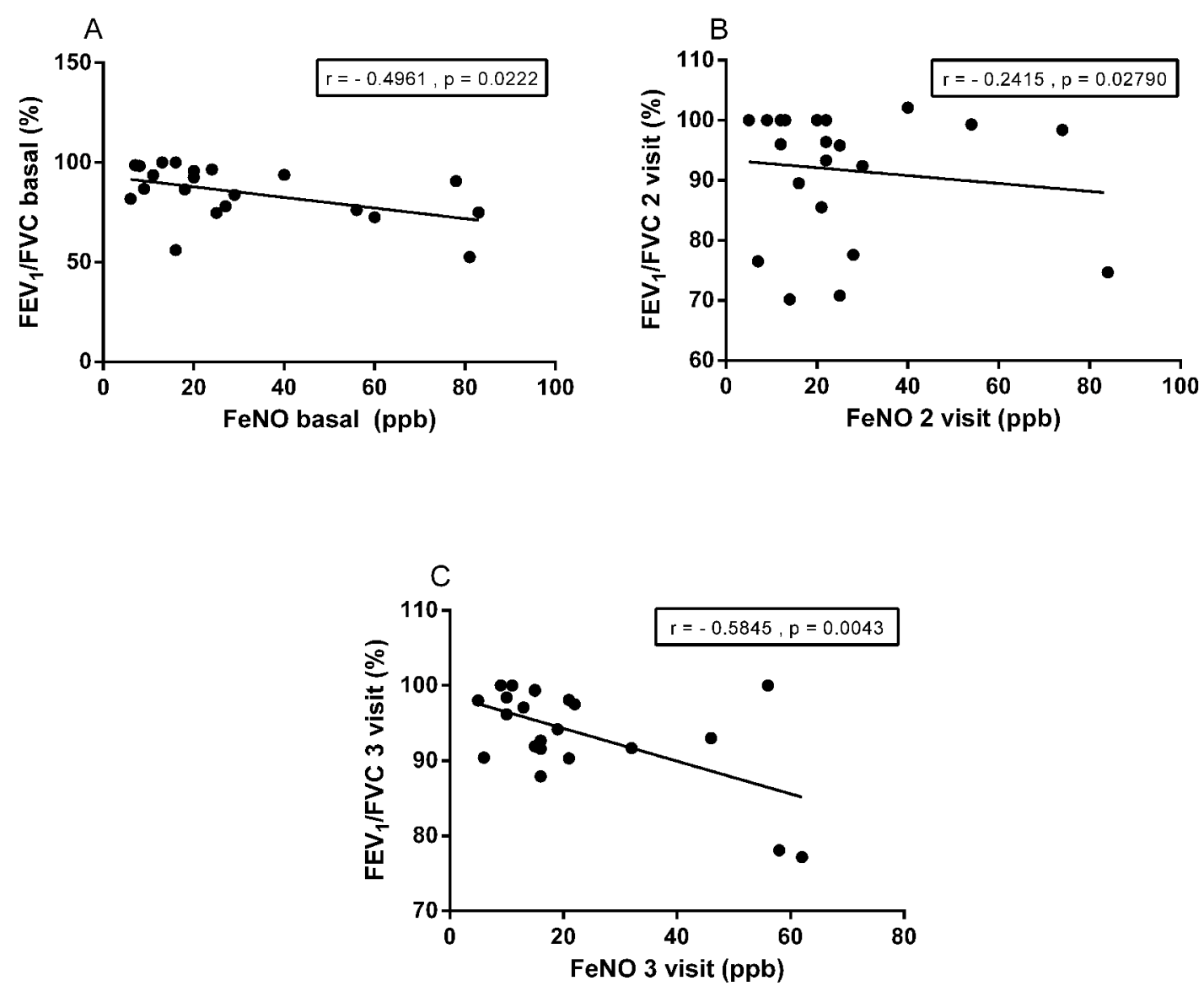

Figure 2: Relationship of fractional of exhaled nitric oxide (FeNO) and Tiffeneau index, the baseline visits, $2^{\text {nd }}$ and $3^{\text {rd }}$ visits. 

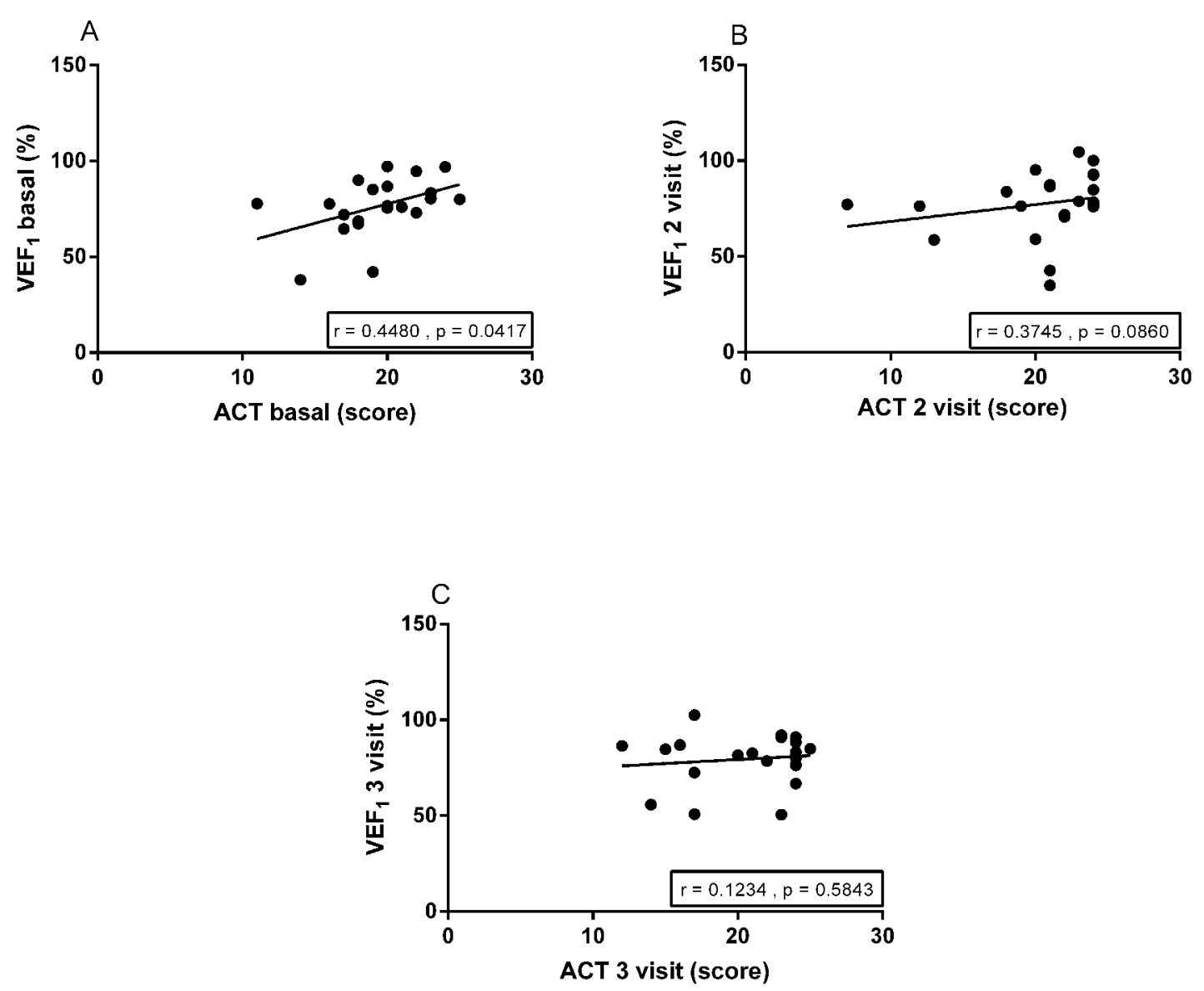

Figure 3: Correlation of the asthma control test (ACT) and forced expiratory volume in the first second of forced vital capacity $\left(\mathrm{FEV}_{1}\right)$, the baseline visits, $2^{\text {nd }}$ and $3^{\text {rd }}$ visits.

Inhaled corticosteroids have been considered as first-line treatment in adults and children who have persistent asthma. The corticosteroids suppress inflammation by positively affects the airway inflammation and asthma symptoms in most patients. Its main action is to inhibit the inflammatory genes encoding cytokines, chemokines, adhesion molecule, enzymes and inflammatory receptors [28].

One of the strategies used to monitor asthma control and response to anti-inflammatory agents such as corticosteroids, is the assessment of the level of exhaled nitric oxide, a marker of airway inflammation. The FeNO was the first and is the most widely marker inflation airway used [9]. According to some authors the level of FeNO predicts the likelihood of responding to corticosteroids more consistently than spirometry, bronchodilator response, variability of peak expiratory flow (PEF) and hiperresponsividade to methacholine [29-31]. Other authors have shown that FeNO can be used as a marker of asthma control [21] and that this present rapid response to treatment modification [32]. However, studies using FeNO as an alternative method to modify treatment with corticosteroids based on symptoms and/or pulmonary function are conflicting [33]. For the analysis of the exhaled results, patients in this study were divided into two subgroups, age $\geq 12$ and $\leq 11$ years, according to the cutoff point recommended by the manufacturer. Levels of FeNO were significantly higher in children aged $\geq 12$ years $(48.9 \pm 31.1 \mathrm{ppb})$ compared to those aged $\leq 11$ years $(21.7 \pm 16.1 \mathrm{ppb})$. However, both values were classified as intermediaries in their respective populations. It was also observed that the dispersion of FeNO values was high in both age groups, in all visits. These results are in agreement with data [34] evaluating asthmatic children and adolescents (7 - 17 years) and found that FeNO levels ranged from 17 to $56.2 \mathrm{ppb}$. No present study was also observed that FeNO correlated significantly between the three measures.

Several authors have shown that the exhaled nitric oxide levels are high primarily in atopic asthma $[9,35,36]$. In this study, FeNO levels did not differ between participants with atopic asthma, non-atopic, the three conditions. In contrast, [36] demonstrated that atopic asthmatics with moderate persistent asthma and severe (6-17 years) and use of anti-inflammatory medication for at least one year, have higher levels of exhaled nitric oxide, suggesting the persistence of inflammatory activity despite the use of antiinflammatory medication. Similar to the data presented by [34], a wide dispersion was observed the FeNO levels at every visit, regardless of the age range studied. The wide dispersion of FeNO levels and the small number of participants may explain the difference in results. As can 
be seen in Table 2, the number of asthma patients with low levels of exhaled increased from 9 to 16 patients, considering the first and third visits. Moreover, the number of asthma patients with intermediate levels of exhaled reduced from 8 to 2 patients, given the same period. As the number of patients with high levels of exhaled remained constant throughout the visits, these results suggest that treatment with corticosteroids decreased airway inflammation in this population.

In relation to data in lung function was observed that $\mathrm{FEV}_{1}(\%)$ did not vary significantly between visits. Otherwise, the $\mathrm{FEV}_{1} / \mathrm{FVC}$ ratio (\%) significantly increased basal query to the third visit, suggesting improvement in lung function. Unlike many authors $[34,37]$ that found no association between reduction in FeNO levels with improved lung function in this study the FeNO levels inversely correlated with the Tiffeneau index, assessed at baseline as well in the second and third visits. These results suggest reduction of inflammation was accompanied by an improved pulmonary function. Our results corroborate those of Yao, et al. [38] who observed correlation between levels of FeNO and FVC, $\mathrm{FEV}_{1}$ and $\mathrm{FEV}_{1} / \mathrm{FVC}$. FEV 1 levels (\%), the FVC, $\mathrm{FEV}_{1} / \mathrm{FVC}$ ratio (\%), and $A C T$ scores did not differ between atopic and non-atopic subgroups in 3 time points.

This study has some limitations. Due to the small sample size, the FeNO levels were not measured in sub-groups according to gender. Hervás, et al. [34] and Zhang, et al. [39] demonstrated that FeNO levels in males are higher than females. Another limitation was the selection of patients. In this study the prevalence of diseases related to atopy has not been established. Levels of FeNO may appear to change in various conditions such as rhinitis and atopic eczema, leading to difficulty in interpreting the results. Finally, the cutoff used in this study to establish the limits of normality, were those recommended by the manufacturer. However, this inflammatory marker, and is modulated by several factors such as age, gender, height, ethnicity, heterogeneity of asthma phenotypes and diseases related to atopy, it is also modulated by environmental factors (smoking, environmental pollution, the measurement time, season) $[9,40]$.

\section{Conclusion}

This study showed that treatment with corticosteroids improved the classification of the level of asthma control and that despite the great dispersion of the FeNO levels, it correlated inversely with Tiffeneau index at the three assessments.

\section{Acknowledgments}

This work was supported by the Fundação Lucas Machado (FELUMA), Faculdade Ciências MédicasMinas Gerais, Pós Graduação em Ciências da Saúde and Pneumology Pediatric Clinic of Unidade de Referência de Saúde Campos Sales, da Prefeitura de Belo Horizonte
(URS Campos Sales- SUS BH). We are thankful to Isabel Cristina Gomes for statistical analysis assistance.

\section{Conflict of Interest}

No conflict of interest exist.

\section{Author's Contributions}

UOA- Conception and design, acquisition of data, analysis and interpretation of data, drafting the article, revised and approved final version of manuscript; GSMAnalysis and interpretation of data, edited and revised manuscript, approved final version of manuscript; NSJConception and design, analysis and interpretation of data, drafting the article, revised and approved final version of manuscript; MGRM- Conception and design, analysis and interpretation of data, drafting the article, revised and approved final version of manuscript.

\section{References}

1. Global Initiative for Asthma (2016) Global strategy for asthma management and prevention: Online appendix.

2. Bel EH (2004) Clinical phenotypes of asthma. Curr Opin Pulm Med 10: 44-50.

3. Gamble J, Stevenson M, McClean E, Heaney LG (2009) The prevalence of nonadherence in difficult asthma. Am J Respir Crit Care Med 180: 817-822.

4. Rincon M, Irvin CG (2012) Role of IL-6 in asthma and other inflammatory pulmonary diseases. Int J Biol Sci 8: 12811290.

5. Silkoff PE, Lent AM, Busacker AA, Katial RK, Balzar S, et al. (2005) Exhaled nitric oxide identifies the persistent eosinophilic phenotype in severe refractory asthma. J Allergy Clin Immunol 116: 1249-1255.

6. Ricciardolo FL, Sorbello V, Ciprandi G (2015) A pathophysiological approach for FeNO: A biomarker for asthma. Allergol Immunopathol (Madr) 43: 609-616.

7. Ricciardolo FL, Sorbello V, Bellezza Fontana R, Schiavetti I, Ciprandi G (2015) Exhaled nitric oxide in relation to asthma control: A real-life survey. Allergol Immunopathol (Madr) 44: 197-205.

8. Matsunaga K, Hirano T, Oka A, Ito K, Edakuni N (2016) Persistently high exhaled nitric oxide and loss of lung function in controlled asthma. Allergol Int 65: 266-271.

9. Ferrante G, Malizia V, Antona R, Corsello G, Grutta S (2013) The value of FeNO measurement in childhood asthma: Uncertainties and perspectives. Multidiscip Respir Med 8: 50.

10. Nathan RA, Sorkness CA, Kosinski M, Schatz M, Li JT, et al. (2004) Development of the asthma control test: A survey for assessing asthma control. J Allergy Clin Immunol 113: 59-65.

11. Revicki D, Weiss KB (2006) Clinical assessment of asthma symptom control: Review of current assessment instruments. J Asthma 43: 481-487.

12. Schatz M, Sorkness CA, Li JT, Marcus P, Murray JJ, et al. (2006) Asthma control test: Reliability, validity, and responsiveness in patients not previously followed by asthma specialists. J Allergy Clin Immunol 117: 549-556.

13. Lundback B, Dahl R (2007) Assessment of asthma control and its impact on optimal treatment strategy. Allergy 62: 611-619. 
14. Halbert RJ, Tikelman DG, Globe DR, Lin SL (2009) Measuring asthma control is the first step to management: A literature review. J Asthma 46: 659-664.

15. Marchioro J, Gazzotti MR, Nascimento OA, Montealegre F, Fish J, et al. (2014) Level of asthma control and its relationship with medication use in asthma patients in Brazil. J Bras Pneumol 40: 487-494.

16. Miot Hélio Amante (2011) Tamanho da amostra em estudos clínicos e experimentais. J Vasc Bras 10: 275-278.

17. Heinzerling L, Mari A, Bergmann KC, Bresciani M, Burbach G, et al. (2013) The skin prick test - European standards. Clin Transl Allergy 3: 3.

18. Masse MS, Granger Vallée A, Chiriac A, Dhivert-Donnadieu $\mathrm{H}$, Bousquet-Rouanet $\mathrm{L}$, et al. (2011) Comparison of five techniques of skin prick tests used routinely in Europe. Allergy 66: 1415-1419.

19. Fatteh S, Rekkerth DJ, Hadley JA (2014) Skin prick/ puncture testing in North America: A call for standards and consistency. Allergy Asthma Clin Immunol 10: 44.

20. Barbaud A, Goncalo M, Bruynzeel D, Bircher A, European Society of Contact Dermatitis (2001) Guidelines for performing skin tests with drugs in the investigation of cutaneous adverse drug reactions. Contact Dermatitis 45: 321-328.

21. Dweik RA, Boggs PB, Erzurum SC, Irvin CG, Leigh MW, et al. (2011) An official ATS clinical practice guideline: Interpretation of exhaled nitric oxide levels (FENO) for clinical applications. Am J Respir Crit Care Med 184: 602615.

22. Bjermer L, Alving K, Diamant Z, Magnussen $H$, Pavord I, et al. (2014) Current evidence and future research needs for FeNO measurement in respiratory diseases. Respir Med 108: $830-841$.

23. Niox Mino.

24. Shiota N, Yokoyama A, Haruta Y, Hattori N, Kohno N (2011) Association of airway inflammation with asthma control level evaluated by the asthma control test. J Asthma 48: $907-913$

25. Papakosta D, Latsios D, Manika K, Porpodis K, Kontakioti E, et al. (2011) Asthma control test is correlated to FEV1 and nitric oxide in Greek asthmatic patients: Influence of treatment. J Asthma 48: 901-906.

26. Roxo JP, Ponte EV, Ramos DC, Pimentel L, D'Oliveira Júnior A, et al. (2010) Validação do Teste de Controle da Asma em português para uso no Brasil: Validation for use in Brazil. J Bras Pneumol 36: 159-166.

27. Polgar C, Promadhat V (1971) Standard values. In Pulmonary function testing in children: Techniques and standards. ( $1^{\text {st }}$ edn), WB Saunders, Philadelphia, 87-122.
28. Barnes PJ (2011) Biochemical basis of asthma therapy. J Biol Chem 286: 32899-32905.

29. Smith AD, Cowan JO, Brassett KP, Filsell S, McLachlan C, et al. (2005) Exhaled nitric oxide: A predictor of steroid response. Am J Respir Crit Care Med 172: 453-459.

30. Szefler SJ, Martin RJ, King TS, Boushey HA, Cherniack $\mathrm{RM}$, et al. (2002) Significant variability in response to inhaled corticosteroids for persistent asthma. J Allergy Clin Immunol 109: 410-418.

31. Knuffman JE, Sorkness CA, Lemanske RF Jr, Mauger DT, Boehmer SJ, et al. (2009) Phenotypic predictors of longterm response to inhaled corticosteroid and leukotriene modifier therapies in pediatric asthma. J Allergy Clin Immunol 123: 411-416.

32. Grob NM, Dweik RA (2008) Exhaled nitric oxide in asthma. From diagnosis, to monitoring, to screening: Are we there yet? Chest 133: 837-839.

33. Patrick L, Demet I, Andreas J, Bruno K, Heinrich W, et al. (2013) Comparison of treatment guidance based on bronchial responsiveness to mannitol, spirometry or exhaled nitric oxide in stable asthmatic children. Open Journal of Pediatrics 3: 406-417.

34. Hervás D, Milán JM, Garde J (2008) Differences in exhaled nitric oxide in atopic children. Allergol Immunopathol (Madr) 36: 331-335.

35. Silvestri M, Sabatini F, Spallarossa D, Fregonese L, Battistini E, et al. (2001) Exhaled nitric oxide levels in nonallergic and allergic mono- or polysensitised children with asthma. Thorax 56: 857-862.

36. Nulma S Jentzsch, Muriel le Bourgeois, Jacques de Blic, Pierre Scheinmann, Serge Waernessyckle, et al. (2006) Óxido nítrico em criança com asma persistente. J Pediatr (Rio J) 82: 193-196.

37. Verini M, Consilvio NP, Di Pillo S, Cingolani A, Spagnuolo C, et al. (2010) FeNO as a marker of airways inflammation: The possible implications in childhood asthma management. $\mathrm{J}$ Allergy (Cairo).

38. Yao TC, Ou LS, Lee WI, Yeh KW, Chen LC, et al. (2011) Exhaled nitric oxide discriminates children with and without allergic sensitization in a population-based study. Clin Exp Allergy 41: 556-564.

39. Zhang H, Shu L, Cai X, Wang Z, Jiao X, et al. (2013) Gender and age affect the levels of exhaled nitric oxide in healthy children. Exp Ther Med 5: 1174-1178.

40. La Grutta S, Ferrante G, Malizia V, Cibella F, Viegi G (2012) Environmental effects on fractional exhaled nitric oxide in allergic children. J Allergy (Cairo). 